\title{
Leflunomide Increases Hepatic Exposure to Methotrexate and Its Metabolite by Differentially Regulating Multidrug Resistance-Associated Protein Mrp2/3/4 Transporters via Peroxisome Proliferator-Activated Receptor $\alpha$ Activation $\$$
}

\author{
Le Wang, Leilei Ma, Yunfei Lin, Xing Liu, Ling Xiao, Yiting Zhang, Ye Xu, Hu Zhou, \\ and Guoyu Pan \\ Shanghai Institute of Materia Medica, Chinese Academy of Sciences, Shanghai, China and University of Chinese Academy of \\ Sciences, Beijing, China
}

Received September 11, 2017; accepted March 26, 2018

\begin{abstract}
Methotrexate (MTX) is the gold standard drug for the treatment of rheumatoid arthritis (RA), and it is frequently combined with leflunomide (LEF) to enhance its clinical efficacy. However, this combination can exacerbate liver toxicity, and the underlying mechanism has not yet been clarified. We investigated whether LEF affects the pharmacokinetics of MTX and its primary toxic metabolite, 7-hydroxyl methotrexate $(7 \mathrm{OH}$ MTX), in mice. LEF significantly increased the plasma concentration (area under the plasma concentration-time curve) of MTX and 7OH MTX (2.4 and 4.5 times, respectively), decreased their bile excretion, and increased their accumulation in the liver and kidneys. When we investigated the effect of LEF on the MTX absorption, distribution, metabolism, and excretion process, we found that LEF had little effect on liver aldehyde oxidase and $7 \mathrm{OH}$ MTX formation. However, LEF
\end{abstract}

significantly decreased the expression of the apical efflux transporter multidrug resistance-associated protein 2 (Mrp2) and increased that of the basolateral efflux transporters Mrp3/4, except there was no significant change in Mrp4 protein expression. Mrp2/3/4 alteration changed the distribution of MTX and 7OH MTX in plasma and tissues. Further studies suggested that LEF indirectly activated peroxisome proliferator-activated receptor $\alpha(\operatorname{PPAR} \alpha)$, which was likely responsible for the Mrp2/3/4 alteration in the liver. The MTX plasma concentration change induced by LEF was reversed by the PPAR $\alpha$-specific antagonist GW6471. These results may partially explain the exacerbated liver toxicity caused by combination treatment with MTX and LEF and may raise concerns regarding the risk of potential drug-drug interactions between PPAR $\alpha$ agonists and Mrp substrates in the clinic.

\section{Introduction}

Rheumatoid arthritis (RA) is a systemic autoimmune disease that primarily causes chronic erosion of the joints (McInnes and Schett, 2011), and it is currently the most frequently occurring autoimmune arthritis (Lawrence et al., 2008). Methotrexate (MTX) is the first choice and most widely

This work was supported by the "Organ Reconstruction and Manufacturing" Strategic Priority Research Program of the Chinese Academy of Sciences [Grant XDA16000000], the Independent Deployment Program of the Institute of Pharmaceutical Innovation of the Chinese Academy of Sciences [Grant CASIMM0120163012], the Hundred Talents Program of the Chinese Academy of Sciences, and the National Science Foundation of China [Grant 81573499]. https://doi.org/10.1124/mol.117.110593.

S This article has supplemental material available at molpharm. aspetjournals.org. recommended drug for the treatment of RA (Singh et al., 2016). However, MTX is also widely reported to induce liver toxicity (Visser and van der Heijde, 2009), which not only causes acute injury but also increases the risk of fibrosis and cirrhosis due to long-term use (Ashton et al., 1982; Zachariae et al., 2001).

During RA therapy, it is recommended that patients combine MTX with other drugs if MTX monotherapy fails to achieve a satisfactory curative effect. Leflunomide (LEF) is one of the most frequently chosen drugs for use in combination with MTX (Singh et al., 2016). Many clinical reports have suggested that the combination induces better therapeutic effects (Weinblatt et al., 1999; Kremer et al., 2002; Dendooven et al., 2006). However, compared with MTX or LEF monotherapy, the combination therapy significantly increases liver toxicity, with pronounced increases in aspartate

ABBREVIATIONS: 7OH MTX, 7-hydroxyl methotrexate; Ahr, aryl hydrocarbon receptor; AOX, aldehyde oxidase; AUC, area under the plasma concentration-time curve; BAP, benzopyrene; Car, constitutive androstane receptor; Fxr, farnesoid X receptor; GAPDH, glyceraldehyde-3phosphate dehydrogenase; GFT505, 2-[2,6-dimethyl-4-[(E)-3-(4-methylsulfanylphenyl)-3-oxoprop-1-enyl]phenoxy]-2-methylpropanoic acid; GW647, 2-(4-(2-(1-cyclohexanebutyl-3-cyclohexylureido)ethyl)phenylthio)-2-methylpropionic acid; GW6471, N-[(2S)-3-[4-[2-(5-methyl-2-phenyl1,3-oxazol-4-yl)ethoxy]phenyl]-2-[[(Z)-4-oxo-4-[4-(trifluoromethyl)phenyl]but-2-en-2-yl]amino]propyl]propanamide; HET0016, N-hydroxy- $N^{\prime}$-(4butyl-2-methylphenyl)formamidine; LBD, ligand binding domain; LEF, leflunomide; Mrp, multidrug resistance-associated protein; MTX, methotrexate; $\mathrm{m} / \mathrm{z}$, mass-to-charge ratio; PEG400, polyethylene glycol 400; PK, pharmacokinetics; PPAR $\alpha$, peroxisome proliferator-activated receptor $\alpha$; Q-PCR, quantitative real-time polymerase chain reaction; RA, rheumatoid arthritis; UA, Urea buffer. 
transaminase and alanine transaminase levels (Weinblatt et al., 2000; Curtis et al., 2010; Londono et al., 2012). In addition, LEF increases the risk of silent liver fibrosis in patients with RA receiving MTX (Lee et al., 2012). Toxicity experiments in rats also reproduced this phenomenon after long-term coadministration of MTX/LEF (Bilasy et al., 2015). However, the mechanism underlying the increased liver toxicity remains unclear.

MTX is metabolized by the cytosolic drug-metabolizing enzyme aldehyde oxidase (AOX) (mainly the AOX1 and AOX3 subtypes) to 7-hydroxyl methotrexate (7OH MTX), the primary toxic metabolite of MTX in both humans and rodents (Kitamura et al., 1999). The acute lethal dose of 7OH MTX is less than $10 \%$ that of MTX in rodents, and the plasma concentration of 7OH MTX is employed as a monitoring index of MTX toxicity in the clinic (Fuskevåg et al., 2000). MTX and 7OH MTX are predominately taken up by folate acid transporters and excreted by canalicular efflux transporters, such as multidrug resistance-associated protein 2 (Mrp2), P-glycoprotein, and breast cancer resistance protein, or basolateral efflux transporters, such as Mrp3 and Mrp4, in both humans and mice (Payet et al., 1988; Vlaming et al., 2009a,b). LEF is a widely reported agonist of the aryl hydrocarbon receptor (Ahr) and an inducer of the Cyp1A/1a subfamily in both humans and rodents (Iqbal et al., 2013; Kim et al., 2015). However, the effect of LEF on other Ahr target genes, such as AOX and several efflux drug transporters (Mathieu et al., 2001; Rivera et al., 2005; Gu and Manautou, 2010; Tan et al., 2010; Xu et al., 2010), has not been well elaborated. We speculated that LEF may induce AOX activity and/or influence the functions of transporters that alter liver excretion of MTX and its toxic metabolite 7OH MTX. These combined effects may play a role in increasing MTX liver toxicity. Considering that the pharmacokinetic (PK) profile of MTX, the effect of LEF on Ahr activation, and the nuclear receptor regulation of drug metabolism enzymes and transporters are similar in humans and mice (Chan et al., 2013), we investigated the effect of LEF treatment on the PK of MTX in mice.

In this study, in vivo PK and tissue distribution studies were first conducted in mice to evaluate the overall impact of LEF on the disposition of MTX and 7OH MTX in plasma and tissues. To verify our hypothesis and to clarify the underlying mechanism, in vitro studies were conducted. Western blotting and quantitative real-time polymerase chain reaction $(\mathrm{Q}$ PCR) were used to investigate the effect of LEF on the expression of AOX and transporters involved in MTX transport. Microsomes and cytoplasm metabolic tests were conducted to assess the effect of LEF on AOX function. Furthermore, gene screening of nuclear receptors and downstream proteins, proteomics, and in vivo experiments were conducted to confirm and clarify the potential underlying regulatory mechanisms that lead to the MTX and 7OH MTX exposure changes after LEF treatment.

\section{Materials and Methods}

Reagents. LEF was a kind gift from Cinkate Pharmaceutical Intermediates Co. Ltd. (Shanghai, China). Benzopyrene (BAP) (benzo $[a]$ pyrene, catalog no. B1760, 96\% purity; Sigma-Aldrich, St. Louis, MO) was a kind gift from Professor Luan Yang (Hongqiao International Institute of Medicine, Shanghai Tongren Hospital and Faculty of Public Health, Shanghai Jiao Tong University School of
Medicine, Shanghai, China). MTX, phenacetin, and GW6471 (PPAR $\alpha$ antagonist) were purchased from Sigma-Aldrich. HET0016 $[N$ hydroxy- $N$ '-(4-butyl-2-methylphenyl)formamidine; a Cyp4a inhibitor] was purchased from Cayman Chemical (Chicago, IL). GFT505 (2-[2,6-dimethyl-4-[(E)-3-(4-methylsulfanylphenyl)-3-oxoprop-1enyl]phenoxy]-2-methylpropanoic acid; a $\operatorname{PPAR} \alpha$ agonist) was purchased from Medchem Express (Shanghai, China). 7OH MTX was synthesized by SIMR Biotech Co. Ltd. (Shanghai, China).

Acetonitrile, methanol, and formic acid (all high-performance liquid chromatography grade) were purchased from Merck (Darmstadt, Germany). All other analytical-grade reagents were purchased from Sion Pharm Chemical Reagent Co. Ltd. (Shanghai, China) or SigmaAldrich.

Animals and PK Study. The animals used in this study were provided by the Shanghai Laboratory Animal Co. (Shanghai, China). Male C57BL/6 mice (aged 10-12 weeks) were housed in airconditioned animal quarters at a controlled temperature of $23 \pm$ $1.5^{\circ} \mathrm{C}$ and a relative humidity of $70 \% \pm 20 \%$. The mice were fed a standard diet and provided water ad libitum.

Animal experiments were performed according to protocols provided by the Institutional Animal Care and Use Committee of Shanghai Institute of Materia Medica, Chinese Academy of Sciences.

Plasma PK Experiments. For intraperitoneal administration, $4 \mu \mathrm{l} / \mathrm{g}$ body weight of solvent polyethylene glycol 400 (PEG400), $3.125 \mathrm{mg} / \mathrm{ml}$ BAP, $10 \mathrm{mg} / \mathrm{ml} \mathrm{LEF}$, or $10 \mathrm{mg} / \mathrm{ml} \mathrm{LEF}$ plus $1.25 \mathrm{mg} / \mathrm{ml}$ GW6471 ( $N$-[(2S)-3-[4-[2-(5-methyl-2-phenyl-1,3-oxazol-4-yl)ethoxy]phenyl]-2-[[(Z)-4-oxo-4-[4-(trifluoromethyl)phenyl]but-2-en-2-yl]amino]propyl]propanamide) or $1.25 \mathrm{mg} / \mathrm{ml}$ HET0016 was injected into the abdomen of the mice for 3 days. For intravenous administration, $4 \mu \mathrm{l} / \mathrm{g}$ body weight of $12 \mathrm{mg} / \mathrm{ml}$ MTX or $2.5 \mathrm{mg} / \mathrm{ml}$ $7 \mathrm{OH}$ MTX in saline was injected into the tail vein of the mice.

Under isoflurane anesthesia, blood samples were collected from the orbital vein predosing and at 10 minutes, 30 minutes, 1 hour, 2 hours, 4 hours, and 6 hours postdosing. The plasma samples were collected after centrifugation at $6000 \mathrm{~g}$ for 10 minutes and were stored at $-80^{\circ} \mathrm{C}$ until analysis.

Tissue Disposition Study. Tissue samples were collected after intravenous administration of MTX $(50 \mathrm{mg} / \mathrm{kg})$ or $7 \mathrm{OH}$ MTX $(10 \mathrm{mg} / \mathrm{kg})$. Animals were euthanized at 30 minutes or 1 hour, and plasma and tissues (liver, kidney, and small intestine) were collected and stored at $-80^{\circ} \mathrm{C}$ until analysis.

Liquid Chromatography-Tandem Mass Spectrometry. All samples were analyzed using a Shimadzu LCMS-8030 triple quadrupole system (Shimadzu Corp., Kyoto, Japan). The positive electrospray ionization mode was chosen. In addition, the selected reaction monitoring transitions were mass-to-charge ratio $(\mathrm{m} / \mathrm{z}) 454.61 \rightarrow$ 308.4 for MTX, $m / z 471.2 \rightarrow 308.4$ for 7 OH MTX, and $m / z 180.0 \rightarrow$ 110.10 for the internal standard (phenacetin). Analytes were separated using an Inertsil ODS-4 column $(100 \mathrm{~mm} \times 2.10 \mathrm{~mm}, 3 \mu \mathrm{m}$; GL Sciences Inc., Tokyo, Japan). The column temperature was set at $40^{\circ} \mathrm{C}$. The mobile phase was a mixture of acetonitrile and ultrapure water containing $0.1 \%$ formic acid and $5 \mathrm{mM}$ ammonium acetate.

The concentration of phenacetin in the in vitro metabolic study was determined using the same method, with MTX set as an internal standard.

Q-PCR and Western Blotting. Total RNA was extracted from the tissues with TRIzol reagent (Invitrogen, San Diego, CA). cDNA was synthesized using a PrimeScript RT Reagent Kit (Takara, Shiga, Japan). Q-PCR using a SYBR Premix Ex Taq II kit (Takara Biotechnology, Tokyo, Japan) was performed in a Qiagen Rotor Gene Q system (Qiagen, Dusseldorf, Germany). Glyceraldehyde-3-phosphate dehydrogenase (GAPDH) was used for internal normalization. All primers used are listed in Table 1.

Western blot analysis was conducted as previously described (Ni et al., 2016). Briefly, total protein was extracted using radioimmunoprecipitation assay buffer containing the protease inhibitor phenylmethanesulfonyl fluoride. Proteins were separated on $8 \%$ polyacrylamide gels and transferred to polyvinylidene difluoride 
TABLE 1

Primer sequences for Q-PCR analysis

\begin{tabular}{lll}
\hline \multicolumn{1}{c}{ Gene } & \multicolumn{1}{c}{ Forward } & \multicolumn{1}{c}{ Reverse } \\
\hline GAPDH & aactttggcattgtggaagg & acacattgggggtaggaaca \\
AOX1 & actgcgtgggccatcttgtctg & ttcctggccgctatgtgtat \\
Mrp1 & tgcgcttccactcaacatcc & cgggccaggctcacacg \\
Mrp2 & gtgtggattccttgggcttt & cacaacgaacacctgcttgg \\
Mrp3 & gcagagacaggcaatgtgaa & gaaagctgacagcatgacca \\
Mrp4 & catcgcggtaaccgtcctc & ccgcagttttactccgcag \\
Mrp5 & gtctcctttcctctccacatcac & cttgatgcagcctccagatagc \\
Mrp6 & agtcgggaacctgctgaacc & cacgcgctccacggctaccats \\
Bcrp & aaatggagcacctcaacctg & cccatcacaacgtcatcttg \\
P-gp & cagcagtcagtgtgcttacaa & atggctcttttatcggcctca \\
CYP4a10 & tgagggagagctggaaaaga & ctgttggtgatcagggtgtg \\
CYP4a14 & tggggagatcagatccaaag & gacagagtccgccatgattt \\
ACOX1 & caggaaagagcaaggaagtgg & ccttttggctgatcccata \\
CPT1 & ccaggctacagtgggacatt & gaacttgccatgtccttgt \\
Nrf2 & ctttagtcagcgacagaaggac & aggcatcttgtttgggaatgtg \\
Fxr & gcttgatgtgctacaaaagctg & cgtggtgatggttgaatgtcc \\
Pxr & gatggaggtcttcaaatctgcc & cagccggacattgcgtttc \\
Car & ttcaagcctccggctatct & tgatctgttgcaccataaacgtg \\
\hline
\end{tabular}

ACOX1, peroxisomal acyl-coenzyme A oxidase 1; Bcrp, breast cancer resistance protein; CPT1, carnitine palmitoyltransferase I; P-gp, P-glycoprotein; Pxr, pregnane $\mathrm{X}$ receptor.

membranes (GE/Amersham, Little Chalfont, UK). Subsequently, the membranes were blocked with Tris-buffered saline containing 5\% bovine serum albumin for 2 hours and were incubated with primary antibodies overnight at $4^{\circ} \mathrm{C}$. The dilutions of primary antibodies were 1:200 AOX1 (cat. no. sc-98500; Santa Cruz Biotechnology Inc., Dallas, TX), 1:200 Mrp2 (cat. no. sc-5770; Santa Cruz Biotechnology Inc.), 1:200 Mrp3 (cat. no. sc-5774; Santa Cruz Biotechnology, Inc.), and 1:20 Mrp4 (cat. no. ab15602; Abcam, Cambridge, MA). GAPDH (cat. no. 10494-1-AP; Proteintech, Rosemont, IL) was used as a loading reference for the data analyses (we verified that the experimental procedure had no effect on the expression of GAPDH). Subsequently, the membranes were rinsed with Tris-buffered saline containing $0.5 \%$ Tween 80 three times, incubated with horseradish peroxidase-labeled secondary antibodies for 1 hour, rinsed again, and visualized by electrochemiluminescence (Tanon, Shanghai, China) using a Tanon-5200 automatic chemiluminescence image analysis system. Gray intensity analysis of the bands was performed using ImageJ software 1.44p (National Institutes of Health, Bethesda, MD). Briefly, grayscale statistical data were processed for protein bands of interest (AOX1, Mrp2, Mrp3, and Mrp4) and GAPDH expression. In addition, the ratios (interest protein/ GAPDH) were analyzed using a $t$ test (differences between two groups) or one-way analysis of variance (differences between three groups).

In Vitro Metabolic Experiments. Liver cytosol and microsomes were prepared according to the classic protocol with minor alterations (Sugihara et al., 2001). Briefly, mouse liver samples were homogenized and centrifuged at $9000 \mathrm{~g}$ for 20 minutes to obtain S9. Then, S9 was centrifuged at $100,000 \mathrm{~g}$ for 1 hour. After centrifugation, the cytosolic supernatant was collected and the microsomal pellet was resuspended. Protein concentrations were determined using a BCA protein assay kit (Pierce Chemical, Rockford, IL).

Phenacetin was chosen as a probe substrate to determine CYP1a2 activity. Each sample for analysis consisted of $1 \mu \mathrm{M}$ phenacetin, $1 \mathrm{mM}$ nicotinamide adenine dinucleotide phosphate, and $0.4 \mathrm{mg}$ liver microsomes (adjusted protein concentration to $4 \mathrm{mg} / \mathrm{ml}$ ) in a final volume of

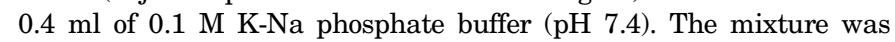
incubated at $37^{\circ} \mathrm{C}$ for 60 minutes. Then, $100 \mu$ l of the mixture was collected immediately after ( 0 minutes) and at 60 minutes after incubation at $37^{\circ} \mathrm{C}$. Subsequently, $300 \mu \mathrm{l}$ ice-cold methanol was added to quench the reactions. The samples were stored at $-80^{\circ} \mathrm{C}$ until analysis. The clearance ratio was calculated as follows: Clearance ratio $=\left(\begin{array}{llll}{[\text { Concentration }} & \text { minutes }) & - \text { Concentration }_{(60} & \text { minutes })\end{array}\right] /$ Concentration $\left._{(0 \text { minutes })}\right) \times 100 \%$.
The formation of 7OH MTX was used to determine the AOX activity. Each sample consisted of $200 \mu \mathrm{M}$ MTX and $0.4 \mathrm{mg}$ liver cytoplasm (adjusted protein concentration to $2 \mathrm{mg} / \mathrm{ml}$ ) in a final volume of $0.4 \mathrm{ml}$ of $0.1 \mathrm{M}$ K-Na phosphate buffer (pH 7.4). The sample mixture was incubated at $37^{\circ} \mathrm{C}$ for 30,60 , or 120 minutes. The reaction was quenched by adding $600 \mu \mathrm{l}$ ice-cold acetonitrile at the indicated time points, and the samples were stored at $-80^{\circ} \mathrm{C}$ until analysis. The AOX activity was presented as the rate of $7 \mathrm{OH}$ MTX formation.

Quantitative Proteomic Analysis. Proteins were digested using the filter-aided sample preparation method. According to the procedure described by Wiśniewski et al. (2009), filter-aided sample preparation was performed using a $30 \mathrm{kDa}$ molecular weight cutoff filter (Microcon; Millipore, Darmstadt, Germany). Briefly, $50 \mu \mathrm{g}$ of each protein extract was mixed with $200 \mu \mathrm{l}$ Urea buffer (UA) solution (8 $\mathrm{M}$ urea in $100 \mathrm{mM}$ Tris- $\mathrm{HCl}, \mathrm{pH}$ 8.5) in the filter unit and centrifuged at $12,000 \mathrm{~g}$ for 25 minutes at $20^{\circ} \mathrm{C}$. Any remaining SDS was washed in a second $200 \mu \mathrm{l}$ UA. Then, the proteins were alkylated with $100 \mu \mathrm{l}$ of $50 \mathrm{mM}$ iodoacetamide for 30 minutes at room temperature. Afterward, $100 \mu \mathrm{l}$ UA was washed three times, followed by another three washing steps with $200 \mu \mathrm{l}$ of $50 \mathrm{mM} \mathrm{NH}_{4} \mathrm{HCO}_{3}$ buffer (Sigma-Aldrich). Proteins were digested by trypsin (Promega, Madison, WI) at an enzyme to substrate ratio of $1: 50(\mathrm{w} / \mathrm{w})$ at $37^{\circ} \mathrm{C}$ for 16 hours. Finally, $200 \mu \mathrm{l}$ of $50 \mathrm{mM} \mathrm{NH}_{4} \mathrm{HCO}_{3}$ was added to elute the resulting peptides. The tryptic peptides were evaporated to dryness in a Speed-Vac sample concentrator. Finally, the digested peptides were eluted and subjected to liquid chromatography-tandem mass spectrometry. Mass spectrum acquisition and data analysis are detailed in the Supplemental Materials and Methods.

PPAR $\alpha$ Luciferase Assay. The PPAR $\alpha$ luciferase assay was conducted as previously described (Xu et al., 2002). Cos-7 cells from American Type Culture Collection (Manassas, VA) were grown to 70\% confluence in Dulbecco's modified Eagle's medium containing 10\% fetal bovine serum. To assess galacto-lectin 4-PPAR $\alpha$ ligand binding domain (LBD) receptors, Cos-7 cells were transiently cotransfected with $200 \mathrm{ng}$ plasmid containing the luciferase gene under the control of the upstream activating sequence element and $100 \mathrm{ng}$ galacto-lectin 4-PPAR $\alpha$ LBD expression plasmid (PPAR $\alpha$ from humans) using Lipofectamine 2000 (Invitrogen, Carlsbad, CA), with 10 ng Renilla luciferase expression plasmid for standardization. Four hours after transfection, the cells were treated with GFT505 $(0.01,0.03,0.1,0.3,1$, 3 , and $10 \mu \mathrm{M})$ and $\operatorname{LEF}(0.1,0.3,1,3,10,30$, and $100 \mu \mathrm{M})$ at the indicated concentrations for 24 hours. Luciferase activity was determined with a reporter luciferase assay kit (Promega) according to the manufacturer's instructions using an Envision luminometer (Perkin-Elmer, Waltham, MA). Luciferase activity was normalized to Renilla luciferase activity. Activity was measured in the presence of vehicle (dimethylsulfoxide) as a control.

Statistical Analysis. Data are expressed as the mean \pm S.D. Differences between two groups were analyzed using the $t$ test. Differences between three or more groups were analyzed using oneway analysis of variance. The raw data were log-transformed and a significant difference analysis was done on the transformed data. $P<$ 0.05 was considered statistically significant.

A noncompartmental analysis utilizing WinNonlin software (version 6.2; Pharsight, Cary, NC) was employed to calculate PK parameters. The maximum plasma concentration $\left(C_{\max }\right)$ and time to reach $C_{\max }$ were directly obtained from observed data, the area under the plasma concentration-time curve (AUC), elimination half-life, systemic plasma clearance, and mean residence time were calculated using a previously described algorithm (Gabrielsson and Weiner, 2012).

\section{Results}

LEF Decreased MTX and 7OH MTX Bile Excretion and Increased Their Concentrations in the Liver, Plasma, and Kidneys. We investigated the effects of LEF 

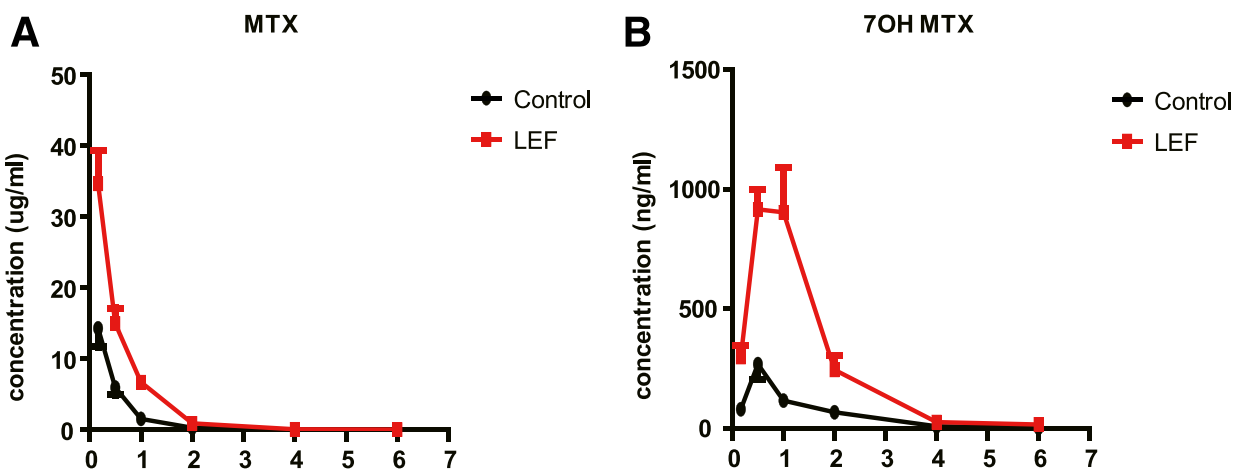

Fig. 1. Effect of LEF treatment on the plasma concentrations of MTX and $7 \mathrm{OH}-$ MTX. (A and B) Concentration-time curves of MTX (A) and 7OH MTX (B). Male C57BL/6 mice were intraperitoneally administered LEF (40 $\mathrm{mg} / \mathrm{kg}$ ) or vehicle (PEG400) for 3 consecutive days, and then all mice were administered MTX $(50 \mathrm{mg} / \mathrm{kg}$, i.v.). Blood samples were collected and analyzed as described in the Materials and Methods. The data are representative of two independent experiments, and each point indicates the mean \pm S.D. $(n=5)$.

on the PK profile of MTX in mice. After LEF ( $40 \mathrm{mg} / \mathrm{kg}$ per day) or PEG400 was administered for 3 consecutive days, mice were injected with a single dose of MTX $(50 \mathrm{mg} / \mathrm{kg})$ via the tail vein. Plasma and tissue concentrations of both MTX and 7OH MTX were determined using liquid chromatography-tandem mass spectrometry.

The results showed that LEF significantly increased the plasma concentration of MTX and 7OH MTX, and the AUCs of MTX and 7OH MTX increased by 2.4 and 4.5 times $(P=0.0019$ and $<0.0001$, respectively; $95 \%$ confidence interval, $1.53-$ to 3.91-fold and 3.35- to 6.19-fold, respectively), respectively. In addition, the $C_{\max }$ of $7 \mathrm{OH}$ MTX increased by 4 -fold $(P=$ $0.0006 ; 95 \%$ confidence interval, 2.30- to 8.39-fold) (Fig. 1; detailed PK parameters presented in Table 2). Furthermore, LEF also markedly altered their tissue distributions. At 1 hour postdose, the concentration of MTX was increased by 4.2 and 3.8 times in the kidneys and liver, respectively $(P=0.0001$ and $<0.0001$, respectively; $95 \%$ confidence interval, $2.65-$ to 6.36-fold and 2.47- to 5.68-fold, respectively), and the concentration of $7 \mathrm{OH}$ MTX was increased by 2.5 and 4.1 times, respectively $(P=0.0003$ and 0.0016 , respectively; 95\% confidence interval, 1.74- to 3.57-fold and 2.01- to 7.77-fold, respectively) (Fig. 2, $\mathrm{A}$ and $\mathrm{B}$ ). In the small intestine, the amount of MTX and 7OH MTX decreased by $35 \%$ and $85 \%$, respectively $(P=0.0926$ and 0.0057 , respectively; $95 \%$ confidence interval, $0 \%-62 \%$ and $73 \%-91 \%$, respectively) (Fig. 2C). The same effect of LEF treatment at 1 hour was observed at 30 minutes postdose but to a lesser extent (Fig. 2). According to a previous study, the MTX/7OH MTX in the intestinal tract within 1 hour after intravenous administration $(50 \mathrm{mg} / \mathrm{kg}$ ) is primarily from bile excretion (Vlaming et al., 2009b). Therefore, we concluded that LEF treatment decreased MTX/7OH MTX bile excretion.

LEF Slightly Induced AOX Expression and Function, But Altering AOX Had a Minimal Effect on the PK Profiles of MTX and 7OH MTX. We investigated the effect of LEF on the expression and function of AOX, which plays a key role in transforming MTX to 7OH MTX. The Q-PCR results revealed that LEF significantly activated $\mathrm{Ahr}$, resulting in significant upregulation of CYP1a2 gene expression, a classic downstream target of Ahr (4.9 times; $P=0.0001 ; 95 \%$ confidence interval, 2.77- to 8.08-fold) (Fig. 3A). The clearance of phenacetin, a probe substrate of CYP1a2, was also increased in liver microsomes of LEF-treated mice (1.5 times; $P=0.013 ; 95 \%$ confidence interval, 1.05 - to 2.51 -fold) (Fig. 3B). However, the Q-PCR and Western blot results indicated that LEF only slightly induced gene and protein expression of AOX1 (2 and 1.6 times, respectively; $P=0.39$ and 0.46 , respectively; $95 \%$ confidence interval, 0.65 - to 4.06 -fold and 0.59 - to 3.47 -fold, respectively). In addition, the liver cytoplasm metabolism results showed that LEF only increased 7OH MTX formation by 1.4 -fold ( $P=0.0046$; $95 \%$ confidence interval, 1.19- to 1.65-fold) (Fig. 3, C-E).

In contrast, the administration of BAP, which is a stronger Ahr agonist, at $12.5 \mathrm{mg} / \mathrm{kg}$ per day intraperitoneally for 3 days significantly upregulated the gene and protein expression of AOX1 (two and four times, respectively; $P=0.011$ and 0.002 , respectively; 95\% confidence interval, 1.32 - to 3.16 -fold and 2.77- to 6.30-fold, respectively) (Fig. 3, C and D) and the formation of $7 \mathrm{OH}$ MTX (1.9 times; $P<0.0001$; $95 \%$ confidence interval, 1.58- to 2.35-fold) (Fig. $3 \mathrm{E}$ ). We then used BAP to investigate the effect of AOX induction on the PK of MTX.

TABLE 2

PK parameters of MTX and 7OH MTX

PK parameters are presented as the mean \pm S.D. $(n=5)$. The raw data were log-transformed and the significant difference analysis was done on the transformed data.

\begin{tabular}{|c|c|c|c|c|}
\hline \multirow{2}{*}{ PK Parameter } & \multicolumn{2}{|c|}{ MTX } & \multicolumn{2}{|c|}{ 7OH MTX } \\
\hline & Control & LEF & Control & LEF \\
\hline$t_{1 / 2}(\mathrm{~h})$ & $0.53 \pm 0.11$ & $0.41 \pm 0.02$ & $0.91 \pm 0.29$ & $1.26 \pm 0.68$ \\
\hline$T_{\max }(\mathrm{h})$ & NA & NA & $0.80 \pm 0.67$ & $0.75 \pm 0.27$ \\
\hline$C_{\max }(\mu \mathrm{g} / \mathrm{ml})$ & NA & NA & $0.271 \pm 0.143$ & $1.075 \pm 0.320^{* *}$ \\
\hline AUC $\left(\mu \mathrm{g} / \mathrm{ml}^{*} \mathrm{~h}\right)$ & $9.56 \pm 3.39$ & $25.8 \pm 6.5^{*}$ & $0.344 \pm 0.099$ & $1.558 \pm 0.247^{* *}$ \\
\hline CL (1/h per kilogram) & $5.64 \pm 1.54$ & $2.05 \pm 0.51 *$ & NA & NA \\
\hline $\mathrm{MRT}_{0-t}(\mathrm{~h})$ & $0.42 \pm 0.05$ & $0.49 \pm 0.07$ & $1.26 \pm 0.26$ & $1.22 \pm 0.16$ \\
\hline
\end{tabular}

See the illustration in Fig. 1 for details. CL, clearance; $\mathrm{MRT}_{0-t}$, mean residence time from time zero extrapolated until the end of the dosing interval; NA, not applicable; $t_{1 / 2}$, elimination half-life; $T_{\max }$, time to reach $C_{\text {max }}$

$* P<0.01 ; * * P<0.001$ (differences between two groups were analyzed using the $t$ test). 

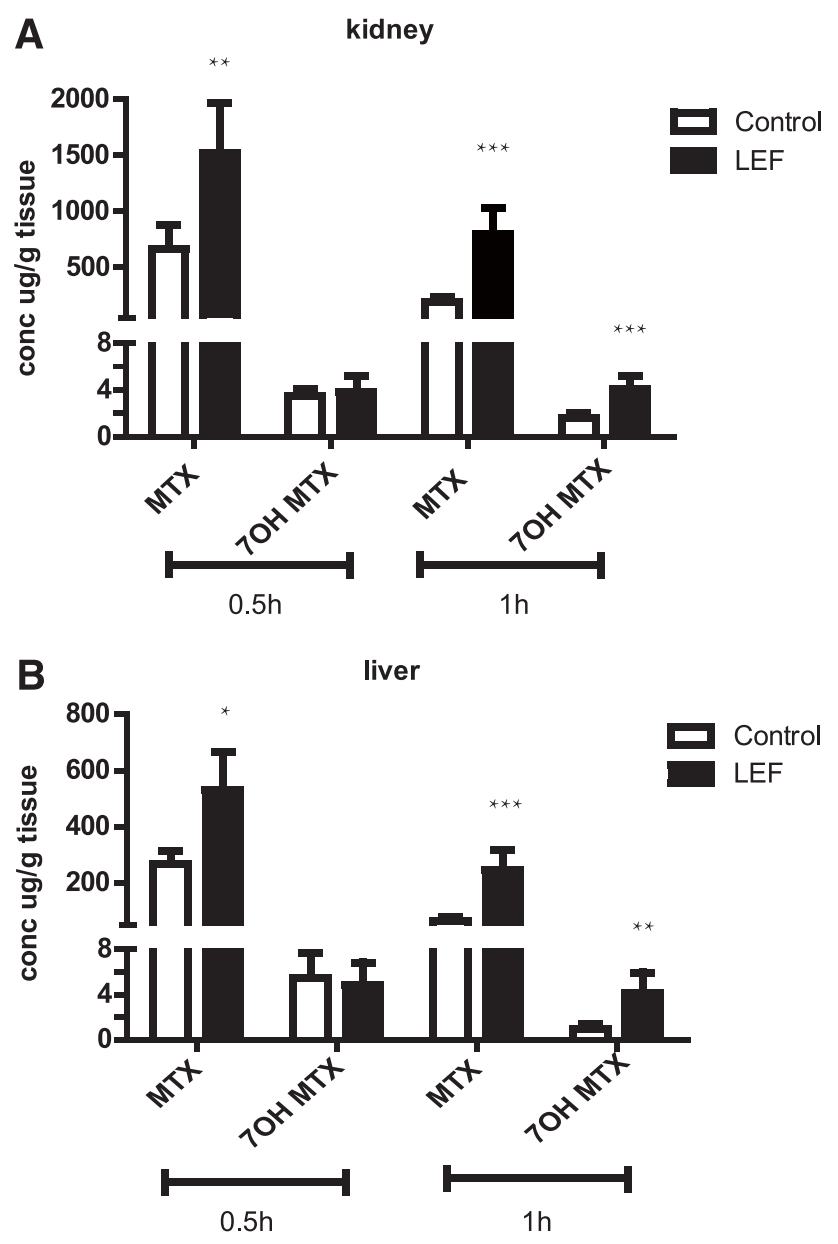

C small intestine and content

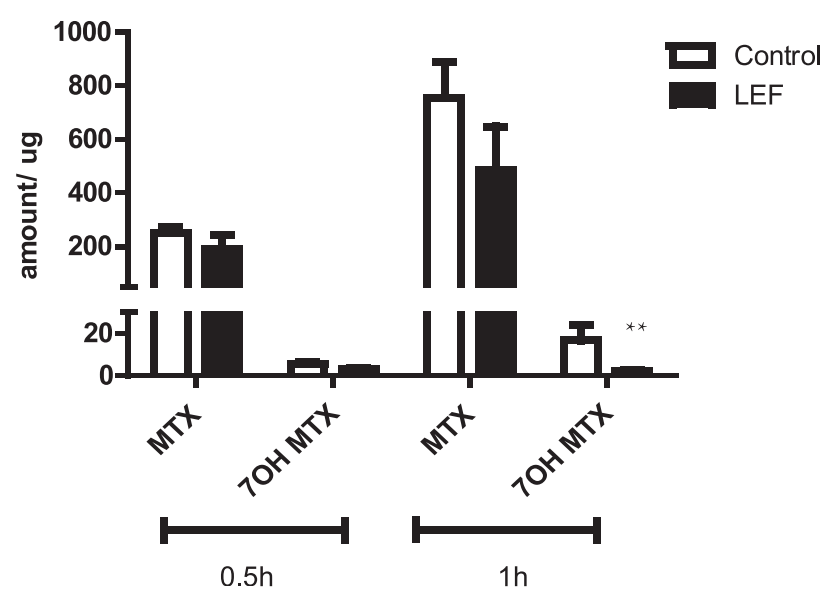

Fig. 2. Effect of LEF treatment on the tissue distributions of MTX and 7OH-MTX. (A-C) The concentrations (conc) of MTX and 7OH MTX in the kidney (A), liver (B), and small intestine (C) were assessed at 30 minutes and 1 hour. Male C57BL/6 mice were intraperitoneally administered LEF $(40 \mathrm{mg} / \mathrm{kg}$ ) or vehicle (PEG400) for 3 consecutive days, and then all mice were administered MTX ( $50 \mathrm{mg} / \mathrm{kg}$, i.v.). At 30 minutes and 1 hour after the last dose, the mice were euthanized and tissue samples were collected and analyzed as described in the Materials and Methods. The data are representative of two independent experiments, and each point indicates the mean \pm S.D. $(n=5)$. The raw data were log-transformed and the significant difference analysis was done on the transformed data. Differences between two groups were analyzed using the $t$ test $\left({ }^{*} P<0.05\right.$; ** $P<$ $0.01 ; * * P<0.001)$.
Although BAP significantly upregulated the expression and function of AOX, it had no effect on the plasma concentration and tissue distribution of MTX and 7OH MTX in mice (Fig. 3, G-I).

LEF Significantly Decreased Mrp2 Expression and Increased Mrp3 Expression. We then investigated the effect of LEF on liver efflux transporters that facilitate pumping of MTX and 7OH MTX out of the liver. Q-PCR analysis indicated that LEF treatment significantly increased the gene expression of Mrp3 (4.9 times; $P=0.0008$; 95\% confidence interval, 2.46- to 9.94-fold) but had no effect on the gene expression of Mrp2 (Fig. 4A). Furthermore, LEF significantly increased the gene expression of Mrp4 (4.2 times; $P=$ $0.0008 ; 95 \%$ confidence interval, 2.22 - to 7.81 -fold) but had no effect on the gene expression of breast cancer resistance protein, P-glycoprotein, Mrp1, Mrp5, and Mrp6 (Fig. 4B) in the livers of mice. Western blot analysis indicated that LEF significantly downregulated Mrp2 protein expression and upregulated Mrp3 protein expression [to 50\% that of the control group (Mrp2) and two times of the control group (Mrp3), respectively; $P<0.0001$ and 0.0007 , respectively; $95 \%$ confidence interval, $41 \%-59 \%$ and 1.52 - to 2.99 -fold, respectively] (Fig. 4, C and D). However, LEF had no effect on protein expression of Mrp4 (Fig. 4, C and D).

LEF Decreased 7OH MTX Bile Excretion and Increased 7OH MTX Concentrations in the Liver, Plasma, and Kidneys after Direct Administration of 7OH MTX in Mice. Considering the significant influence of LEF on the expression of Mrps, we investigated LEF treatment on the 7OH MTX PK profile directly. To exclude the contribution of metabolism from this process, 7OH MTX, the toxic metabolite of MTX, was administered to mice directly after LEF treatment and the plasma and tissue concentrations were measured.

LEF significantly increased the plasma concentration of 7OH MTX, corresponding to a 3.4-fold increase in the AUC of $7 \mathrm{OH}$ MTX $(P=0.0061 ; 95 \%$ confidence interval, 1.57 - to 6.39fold) (Fig. 5A; detailed PK parameters are presented in Table 3). At 30 minutes postdose, the concentration of $7 \mathrm{OH}-$ MTX was increased by 1.2 and 2.4 times in the liver and kidneys, respectively $(P=0.06$ and 0.0003 , respectively; $95 \%$ confidence interval, 0.99 - to 1.51-fold and 1.76- to 3.10-fold, respectively) (Fig. 5, C and D). The amount of 7OH-MTX decreased by $85 \%$ in the intestines $(P=0.001 ; 95 \%$ confidence interval, 67\%-95\%) (Fig. 5B). The same effect of LEF treatment at 1 hour was observed at 30 minutes postdose but to a lesser extent (Fig. 5, B-D).

LEF Upregulated Downstream PPAR $\alpha$ Genes But Is Not a Direct Agonist of PPAR $\alpha$. We examined liver nuclear receptors that had previously been reported to regulate the expression of Mrps in the liver. The gene expression levels of pregnane $\mathrm{X}$ receptor, farnesoid $\mathrm{X}$ receptor (Fxr), constitutive androstane receptor (Car), nuclear factor (erythroid-derived 2) factor 2 (Nrf2), and PPAR $\alpha$ and their target genes (Cyp3a11, Cyp7a1, Cyp2b6, heme oxygenase-1, and Cyp4a10/14, respectively) were screened via a Q-PCR assay. Proteomics analysis was conducted to verify the results. The Q-PCR results showed that LEF exerted very weak effects on the expression of pregnane $\mathrm{X}$ receptor, Fxr, Car, and Nrf2 and their downstream probe genes (Fig. 6, A and B). In addition, none of the abovementioned genes were induced or reduced at the protein level according to proteomics analysis 
A

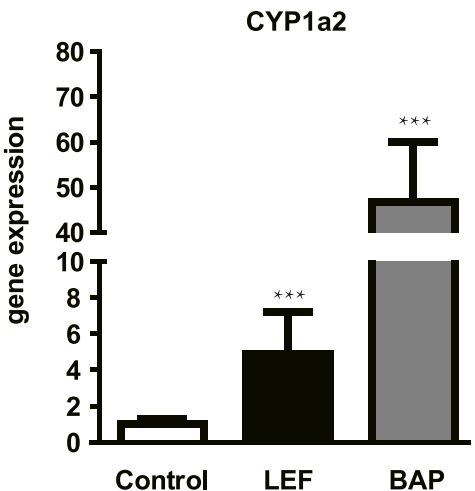

B

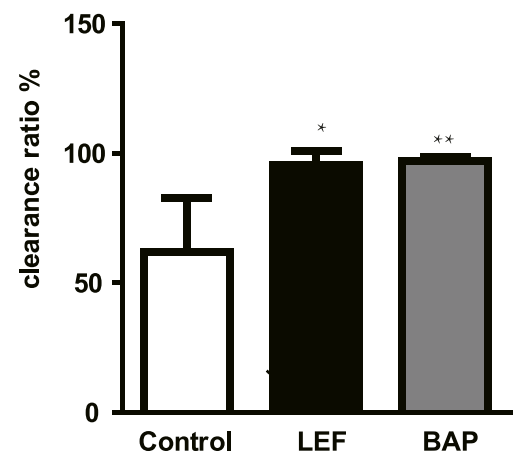

C
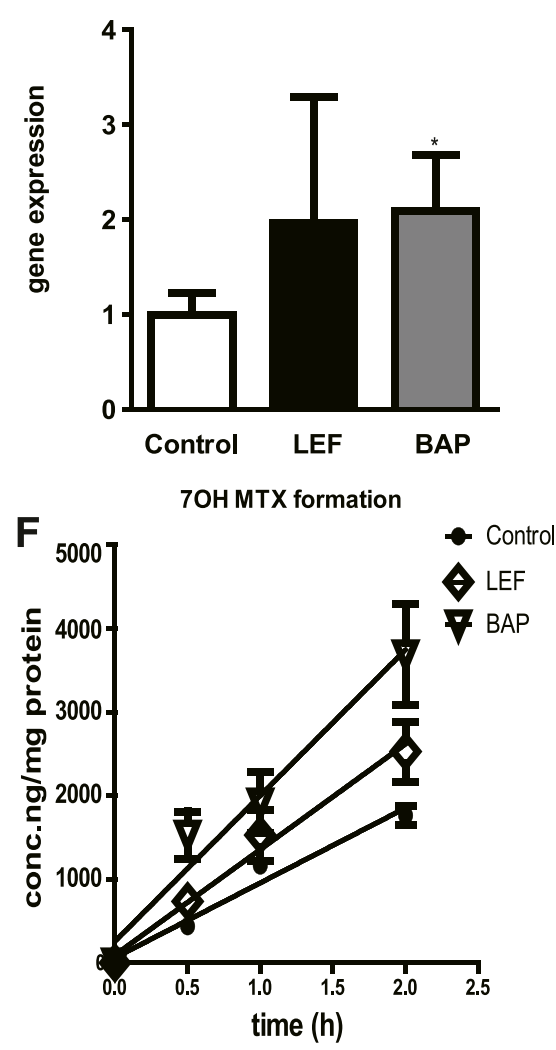

$\mathbf{E}$

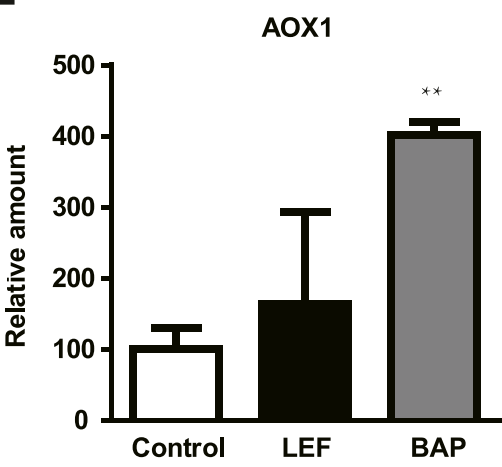

H

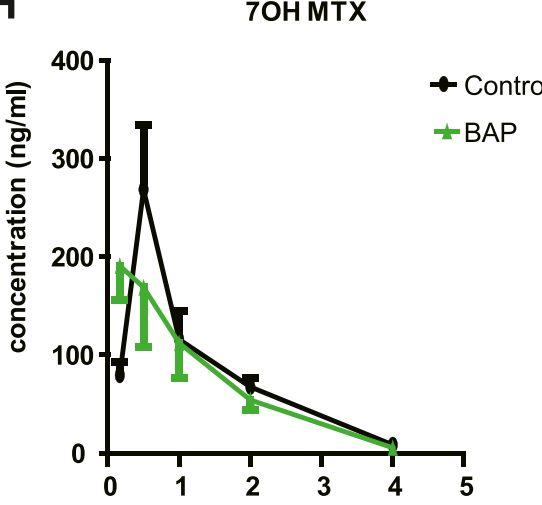

I tissue distribution $(0.5 \mathrm{~h})$

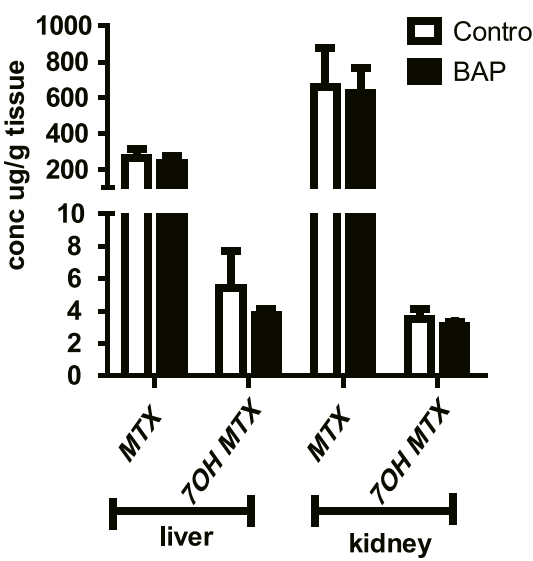

Fig. 3. Effect of LEF treatment on the expression and activity of liver CYP1a2 and AOX. (A and B) Effect of LEF on the gene expression of CYP1a2 (A) and the activity of CYP1a2 (B) in liver microsomes. Phenacetin was chosen as a probe substrate of CYP1a2. (C-E) Effect of LEF on AOX1 gene expression (C) and AOX1 protein expression (D and E). (F) Effect of LEF on AOX activity in the cytoplasm of liver cells. 7OH MTX was chosen as a probe product of AOX. (G and H) Effect of BAP on the plasma concentration of MTX (G) and 7OH MTX (H). (I) Effect of BAP on the liver and kidney concentrations of MTX and 7OH MTX at 30 minutes after the last dose. (A-F) Male C57BL/6 mice were intraperitoneally administered LEF $(40 \mathrm{mg} / \mathrm{kg}$, i.p.), BAP $(12.5 \mathrm{mg} / \mathrm{kg}$, i.p.), or vehicle (PEG400) for 3 consecutive days. The mice were then euthanized, and liver samples were collected and processed as described in the Materials and Methods. BAP was employed as a positive control. Gene expression and Western blotting data were normalized against the endogenous control GAPDH. The data are representative of three independent experiments, and each point indicates the mean \pm S.D. $(n=4)$. The raw data were log-transformed and the significant difference analysis was done on the transformed data. Differences between the three groups were analyzed using one-way analysis of variance $(* P<0.05$; $* * P<0.01$; $* * * P<0.001)$. (G-I) Male C57BL6 mice were intraperitoneally administered BAP (12.5 mg/kg, i.p.) or vehicle (PEG400) for 3 consecutive days, and then all of the mice were administered MTX $(50 \mathrm{mg} / \mathrm{kg}$, i.v.). Blood and tissue samples were collected and the concentration of MTX/7OH MTX were measured. The data are representative of two independent experiments, and each point indicates the mean \pm S.D. $(n=5)$.

(data not shown). However, we found that LEF induced gene expression of the PPAR $\alpha$ nuclear receptor (Fig. 6A) (2.9 times; $P=0.0002 ; 95 \%$ confidence interval, 2.15 - to 4.11 -fold). Furthermore, LEF significantly upregulated the gene expression of CYP4a10 and CYP4a14, which are both downstream targets of PPAR $\alpha$ (5.3 and 9 times, respectively; $P=0.0006$ and 0.0012 , respectively; 95\% confidence interval, 2.71- to 11.38-fold and 3.36- to 29.62-fold, respectively) (Fig. 6B). Moreover, proteomics data showed that the proteins CYP4a10/14 were also significantly upregulated (13 and 5.5 

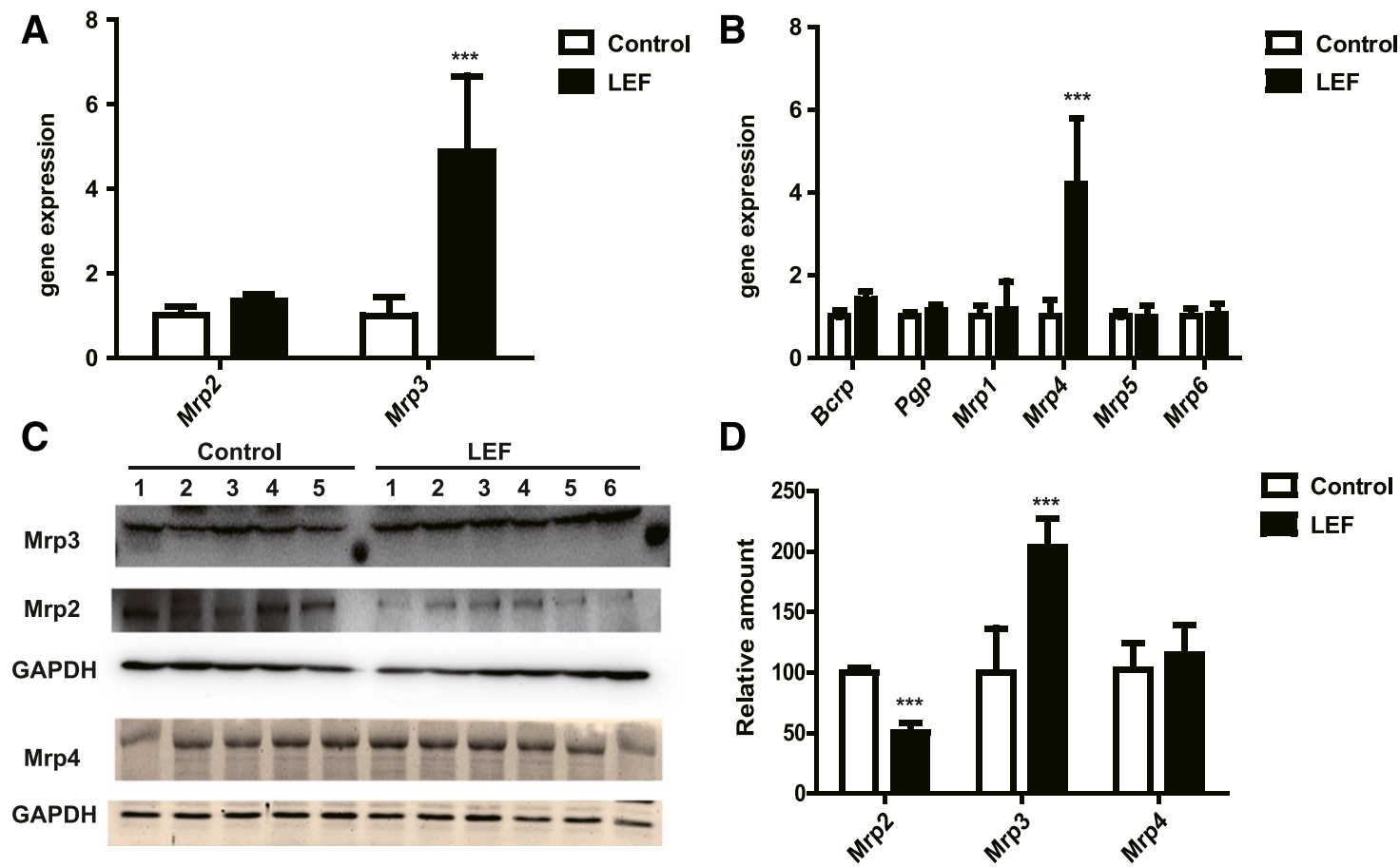

Fig. 4. Effect of LEF treatment on the mRNA and protein expression of liver efflux transporters. (A and B) Gene expression of Mrp2 and Mrp3 (A) and other transporters (Bcrp, P-gp, Mrp1, Mrp4, and Mrp5) (B). (C and D) Protein expression of Mrp2, Mrp3, and Mrp4. Male C57BL/6 mice were intraperitoneally administered LEF (40 mg/kg, i.p.) or vehicle (PEG400) for 3 consecutive days, and then the mice were euthanized. Liver samples were collected and processed as described in the Materials and Methods. Gene expression and Western blotting data were normalized against the endogenous control GAPDH. The data are representative of three independent experiments, and each point indicates the mean $\pm \mathrm{S}$.D. (control, $n=5 ; \mathrm{LEF}, n=6$ ). The raw data were log-transformed and the significant difference analysis was done on the transformed data. Differences between two groups were analyzed using the $t$ test $(* * * P<0.001)$. Bcrp, breast cancer resistance protein; P-gp, P-glycoprotein.

times, respectively; $P=0.01$ and 0.0029 , respectively; $95 \%$ confidence interval, 2.11- to 57.28-fold and 2.03- to 11.22-fold, respectively) (Fig. 6C). Nonetheless, our data suggested that LEF was not a direct agonist of the PPAR $\alpha$ nuclear receptor according to the $\operatorname{PPAR} \alpha$ luciferase reporter assay results (Fig. 6D).

PPAR $\alpha$ Inhibition Reversed the Effect of LEF on the PK Profile of MTX/7OH MTX. We further verified whether LEF affects the PK profile of MTX and 7OH MTX through activation of $\operatorname{PPAR} \alpha$. When LEF was coadministered with GW6471, a specific PPAR $\alpha$ antagonist, the plasma concentrations of MTX and $7 \mathrm{OH}$ were significantly reduced compared with the concentrations detected after LEF treatment alone (Fig. 7). In particular, GW6471 almost completely reversed the effect of LEF on MTX plasma concentrations.

Because CYP4Aa10/14 was dramatically upregulated during $\operatorname{PPAR} \alpha$ activation, we tested whether the CYP4a10/14 elevation affected the PK profile of MTX/7OH MTX. We found that the CYP4a-specific inhibitor HET0016 did not reverse the in vivo PK profile of MTX and 7OH MTX after LEF treatment (Fig. 7), which suggests that there is no direct correlation between CYP4a and Mrps (detailed PK parameters are presented in Table 4).

\section{Discussion}

We first investigated the effects of LEF on the PK profile and tissue distribution of MTX in mice. LEF significantly decreased the MTX and 7OH MTX concentrations in the small intestine but increased the levels of these two compounds in the liver, kidneys, and plasma (Figs. 1 and 2). According to a previous report, MTX (and 7OH MTX) is quickly excreted via bile after intravenous injection (Vlaming et al., 2009b). Therefore, LEF likely decreased the biliary efflux of MTX (and 7OH MTX) while increasing the hepatocyte basolateral efflux, subsequently increasing kidney extraction of these two compounds. This effect may diminish the accumulation of MTX and 7OH MTX in the liver but increase the burden on the kidneys, which is also a widely reported MTX toxicity target organ (Widemann and Adamson, 2006). Considering the significant change in the concentration of MTX in the tissues and plasma after LEF treatment, we focused on investigating the effect of LEF treatment on AOX and drug efflux transporters that play key roles in the liver transformation or distribution of MTX to investigate the underlying mechanism.

LEF slightly induced the expression and function of AOX while significantly upregulating Mrp3/4 gene expression. LEF down- and upregulated, respectively, the protein expression of Mrp2 and Mrp3, the two most important liver efflux transporters for MTX (and 7OH MTX) excretion to bile and plasma (Vlaming et al., 2009a,b), and had no effect on protein expression of Mrp4.

As a well-known Ahr inducer, LEF's impacts on the PK profile of MTX are likely linked to Ahr activation. However, as a much more powerful agonist of Ahr, BAP showed a markedly stronger induction of AOX and had no effect on the gene and protein expression of Mrp2/3/4 (Supplemental Fig. 1). Importantly, BAP did not alter the PK profiles and tissue distributions of MTX and 7OH MTX after MTX administration. BAP also did not alter the PK profiles and tissue distributions of 
liver

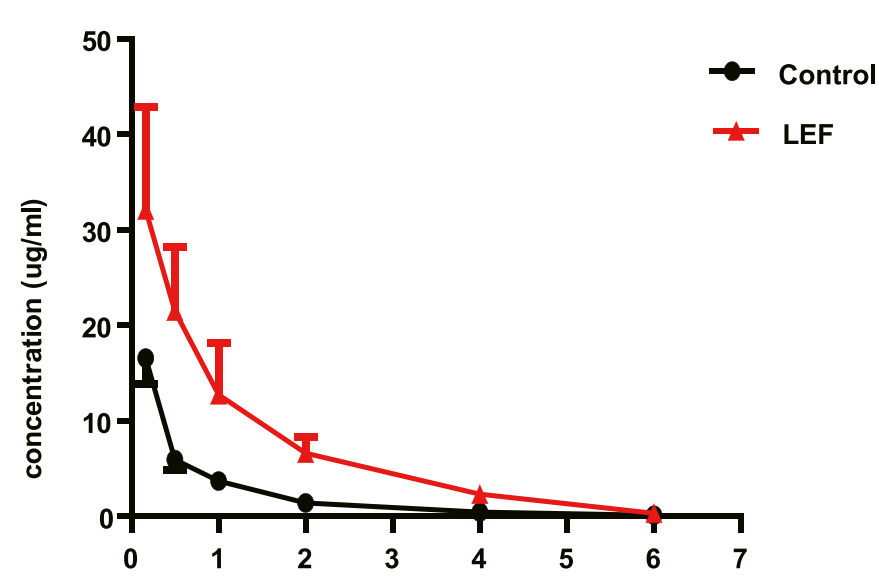

C kidney
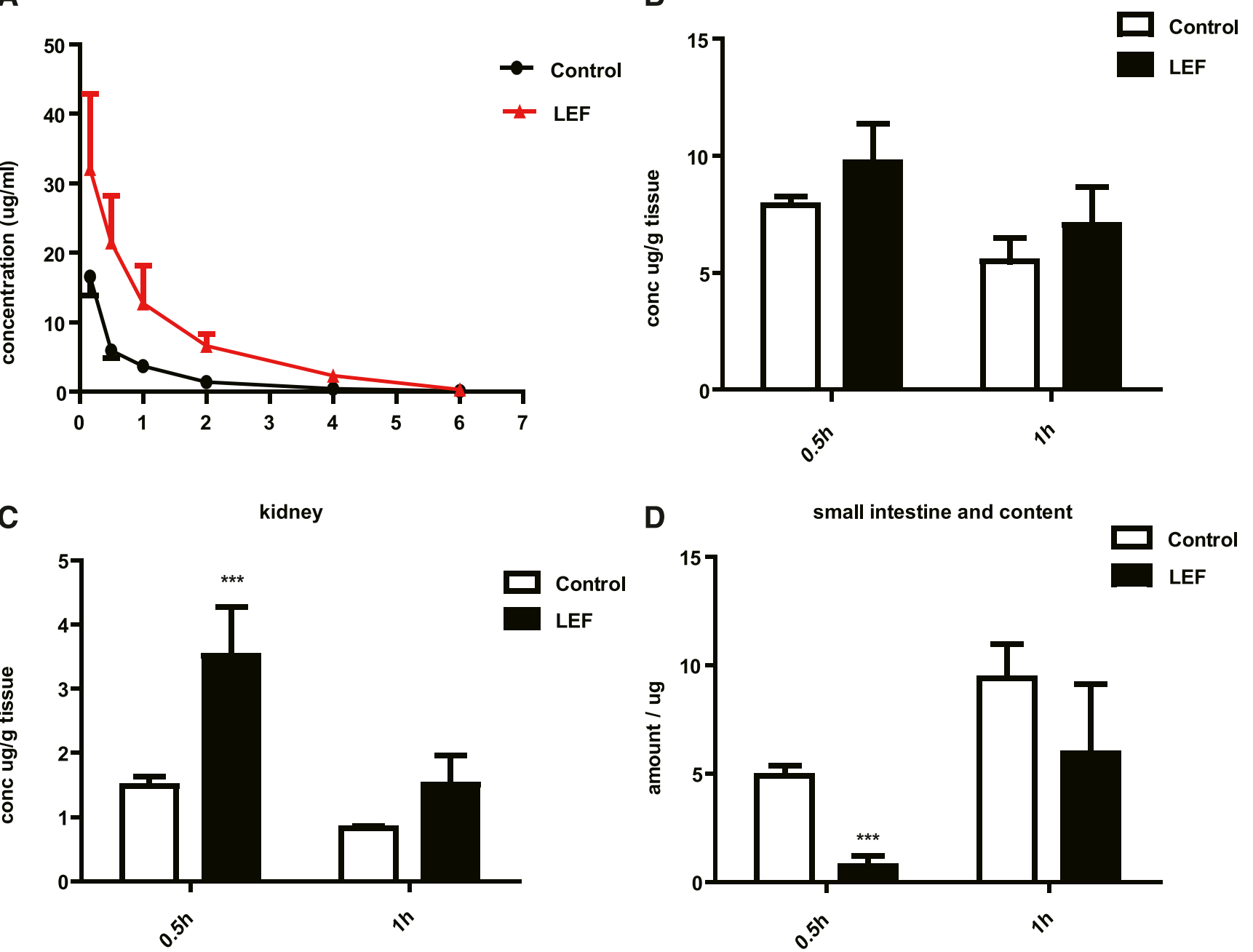

Fig. 5. Effect of LEF treatment on plasma and tissue concentrations of 7OH-MTX after 7OH MTX administration. (A-D) The concentration of 7OH-MTX in the plasma (A) liver (B), kidney (C), and small intestine (D) at 30 minutes and 1 hour after the last dose. Male C57BL/6 mice were intraperitoneally administered LEF $(40 \mathrm{mg} / \mathrm{kg}$ ) or vehicle (PEG400) for 3 consecutive days, and then the mice were administered $7 \mathrm{OH} \mathrm{MTX} \mathrm{(10} \mathrm{mg/kg,} \mathrm{i.v.)} \mathrm{Blood} \mathrm{and} \mathrm{tissue}$ samples were collected and analyzed as described in the Materials and Methods. The data are representative of two independent experiments, and each point indicates the mean \pm S.D. $(n=5)$. The raw data were log-transformed and the significant difference analysis was done on the transformed data. Differences between two groups were analyzed using the $t$ test $(* * * P<0.001)$.

7OH MTX after direct administration of 7OH MTX (Supplemental Fig. 1). In contrast, LEF slightly induced AOX but significantly altered Mrp2/3 expression, which led to a striking alteration in the PK of MTX and/or 7OH MTX. The comparison of BAP and LEF treatment indicated that 1) Ahr may not be a key regulator of MTX PK alterations and 2) alterations in Mrps, rather than AOX induction, may play a key role in the altered PK of MTX after LEF treatment.

We then investigated other liver nuclear receptors (Car, Fxr, Nrf2, and PPAR $\alpha$ ), which also play important roles in regulation of Mrps (Xiong et al., 2002; Moffit et al., 2006; Vollrath et al., 2006; Teng and Piquette-Miller, 2007; Aleksunes et al., 2008). We found that LEF had no significant effect on the expression of Car, Fxr, and Nrf2 or their downstream target genes (CYP2b6, CYP7a1, and heme oxygenase-1, respectively) (Fig. 6). These results indicated that the effect of LEF on Mrps was independent of these nuclear receptors. However, LEF induced gene expression of PPAR $\alpha$ and its downstream target genes CYP4a10, CYP4a14 (Fig. 6), peroxisomal acyl-coenzyme A oxidase 1, and carnitine palmitoyltransferase I (Supplemental Fig. 2) (Lu et al., 2014). Proteomics data showed there was also a significant upregulation of CYP4a10/14 protein expression. Previous studies

\section{TABLE 3}

PK parameters of 7OH MTX

PK parameters are presented as the mean \pm S.D. $(n=5)$. The raw data were logtransformed and the significant difference analysis was done on the transformed data.

\begin{tabular}{lll}
\hline \multirow{2}{*}{ PK Parameter } & \multicolumn{1}{c}{ Control } & \multicolumn{1}{c}{ LEF } \\
& \multicolumn{2}{c}{7 OH MTX } \\
\hline$t_{1 / 2}(\mathrm{~h})$ & $0.91 \pm 0.29$ & $0.99 \pm 0.19$ \\
AUC $\left(\mu \mathrm{g} / \mathrm{ml}{ }^{*} \mathrm{~h}\right)$ & $13.1 \pm 4.6$ & $44.2 \pm 25.6^{*}$ \\
CL $(\mathrm{l} / \mathrm{h}$ per kilogram $)$ & $0.83 \pm 0.27$ & $0.28 \pm 0.13$ \\
$\mathrm{MRT}_{0-t}(\mathrm{~h})$ & $0.82 \pm 0.16$ & $1.28 \pm 0.18$
\end{tabular}

See the illustration in Fig. 5 for details. CL, clearance; $\mathrm{MRT}_{0-t}$, mean residence time from time zero extrapolated until the end of the dosing interval; NA, not applicable; $t_{1 / 2}$, elimination half-life.

$* P<0.01$ (differences between four groups were analyzed using one-way analysis of variance). 

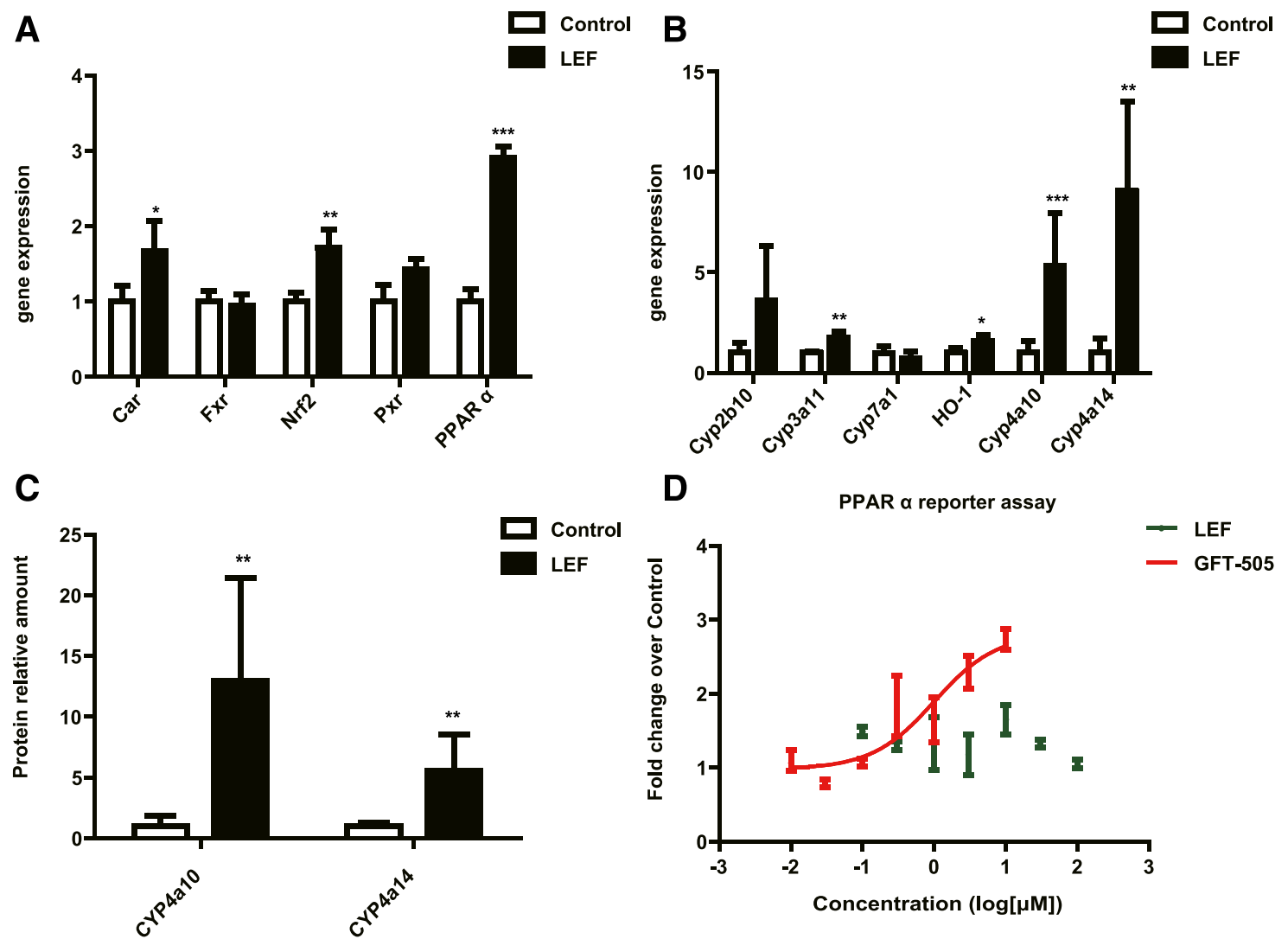

Fig. 6. Effect of LEF treatment on liver nuclear receptors. (A-D) The gene expression of nuclear receptors (Car, Fxr, Nrf2, Pxr, and PPAR $\alpha$ ) (A), downstream target gene expression (CYP2b10, Cyp7a1, HO-1, CYP3a11, CYP4a10, and CYP 4a14) (B), protein expression of Cyp4a10 and Cyp4a14 (proteomics data) (C), and the PPAR reporter luciferase assay (D). (A and B) Male C57BL/6 mice were administered LEF (40 mg/kg) or vehicle (PEG400) for 3 consecutive days, and then the mice were euthanized. Liver samples were collected and processed as previously described in the Materials and Methods. Gene expression was normalized against the endogenous control GAPDH. The data are representative of two independent experiments, and each point indicates the mean \pm S.D. $(n=5)$. (C) Proteomics data showing the relative fold change from the control group (PEG400). Each point indicates the mean $\pm \mathrm{S} . \mathrm{D}(n=5)$. (D) Cos-7 cells were transiently cotransfected with $200 \mathrm{ng}$ plasmid containing the luciferase gene and $100 \mathrm{ng}$ GAL4-PPAR $\alpha$ LBD expression plasmid, and then the cells were treated with GFT-505 (a positive control) and LEF at the indicated concentrations for 24 hours. Luciferase activity was determined and normalized to Renilla luciferase activity. Each condition was performed with $n=3$ for each experiment. As a control, the activity was measured in the presence of vehicle (DMSO). The data are representative of two independent experiments. Each point indicates the mean \pm S.D. The raw data were log-transformed and the significant difference analysis was done on the transformed data. Differences between two groups were analyzed using the $t$ test $\left(* P<0.05 ;{ }^{*} P<0.01\right.$; $\left.{ }^{* *} P<0.001\right)$. DMSO, dimethylsulfoxide; HO, heme oxygenase; Pxr, pregnane $\mathrm{X}$ receptor.

have shown that hepatic expression of Cyp4a genes was almost eliminated after $\operatorname{PPAR} \alpha$ knockout in mice, which suggests that Cyp4a is a PPAR $\alpha$ biomarker (Cyp4a10 and
Cyp4a14 in mice and Cyp4A11 in humans) (Rakhshandehroo et al., 2010); thus, our results imply that LEF significantly activates $\operatorname{PPAR} \alpha$ in the liver of mice. Furthermore, the
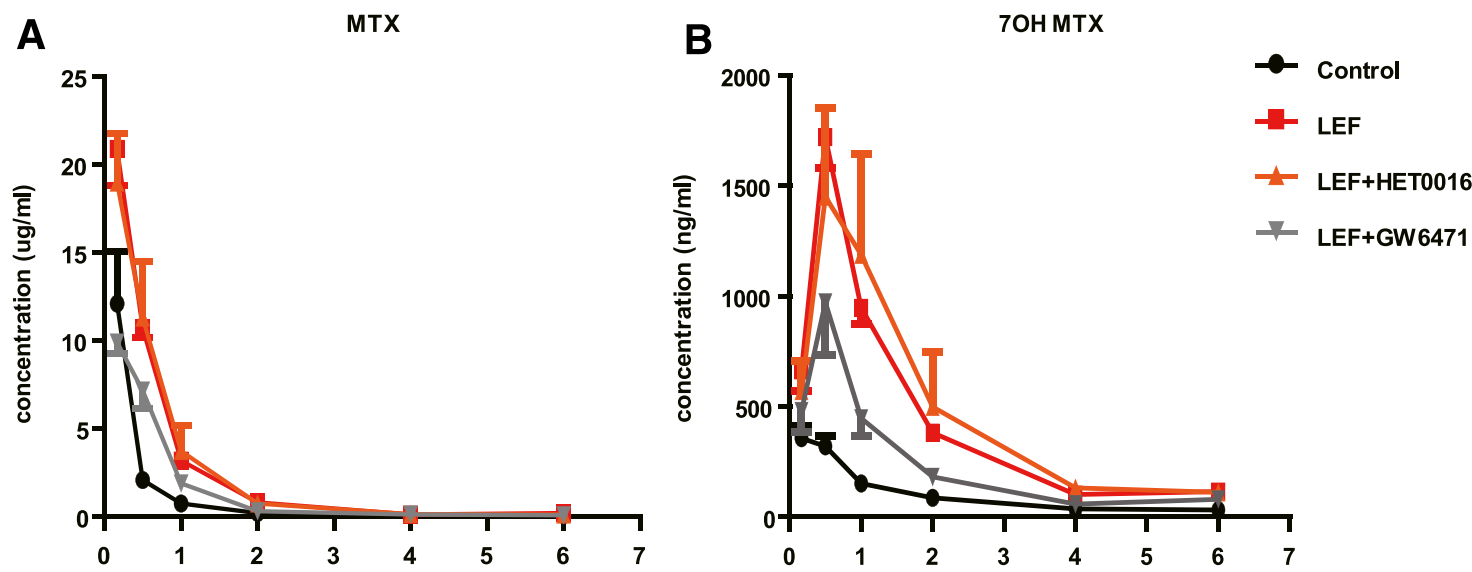

Fig. 7. Effect of LEF, LEF plus HET0016, and LEF plus GW6471 treatment on the plasma concentrations of MTX and 7OH MTX. (A and B)The plasma concentration of MTX (A) and 7OH-MTX (B). Male C57BL/6 mice were administered LEF (40 mg/kg plus 5\% DMSO, i.p.), LEF plus HET0016 (LEF, $40 \mathrm{mg} / \mathrm{kg}$; HET0016, $5 \mathrm{mg} / \mathrm{kg}$, i.p.), LEF plus GW6471 (LEF, $40 \mathrm{mg} / \mathrm{kg}$; GW6471, $5 \mathrm{mg} / \mathrm{kg}$, i.p.), or vehicle (equal volume of PEG400 plus 5\% DMSO) for 3 consecutive days, and then the mice were given a tail vein injection of MTX (50 mg/kg). Blood samples were collected and analyzed as described in the Materials and Methods. The data are representative of two independent experiments, and each point indicates the mean \pm S.D. $(n=5)$. 
TABLE 4

PK parameters of MTX and 7OH MTX

PK parameters are presented as the mean \pm S.D. $(n=5)$. The raw data were log-transformed and the significant difference analysis was done on the transformed data.

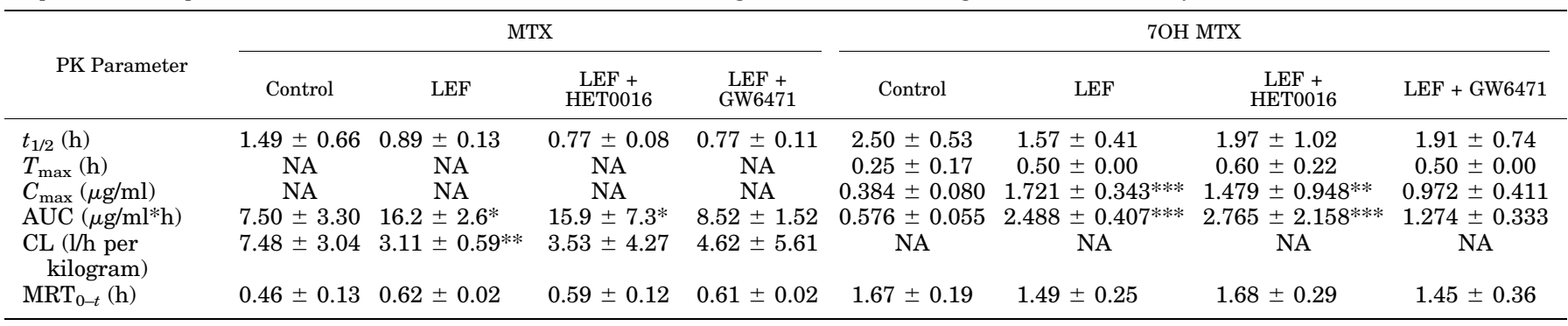

See the illustration in Fig. 7 for details. CL, clearance; $\mathrm{MRT}_{0-t}$, mean residence time from time zero extrapolated until the end of the dosing interval; NA, not applicable; $t_{1 / 2}$, elimination half-life; $T_{\max }$, time to reach $C_{\max }$.

$* P<0.05$; ${ }^{*} P<0.01 ; * * * P<0.001$ (differences between four groups were analyzed using one-way analysis of variance).

proteomics data revealed that LEF also increased the protein level of CYP4A11 in human hepatocytes (Supplemental Table 1). This result indicates that the activation of $\operatorname{PPAR} \alpha$ is consistent between humans and mice. Because there is high homology and the same activation/regulation mechanism between human and mouse PPAR $\alpha$ (Gonzalez and Shah, 2008; Yang et al., 2008), we investigated whether LEF activated $\operatorname{PPAR} \alpha$ through direct structure-transformationmediated $\operatorname{PPAR} \alpha$ activation using a luciferase assay (the human $\operatorname{PPAR} \alpha$ LBD was used in the luciferase assay). The result was negative (Fig. 6). The underlying mechanism should be clarified in future experiments.
According to previous reports, $\operatorname{PPAR} \alpha$ activation can upregulate gene and protein expression of Mrp3/4 (Moffit et al., 2006; Maher et al., 2008) and downregulate Mrp2 protein expression but had no influence on Mrp2 gene expression (Johnson and Klaassen, 2002). The abovementioned regulation of Mrp2/3/4 via PPAR $\alpha$ is consistent with our findings after LEF treatment except that the protein expression of Mrp4 was unchanged. However, the disconnection between gene expression and protein expression of efflux transporters is very common under xenobiotic treatment or disease state, possibly due to complex and sophisticated stress response and regulation mechanism of those efflux transporters $(\mathrm{Gu}$ and

\section{PK profile tissue distribution}
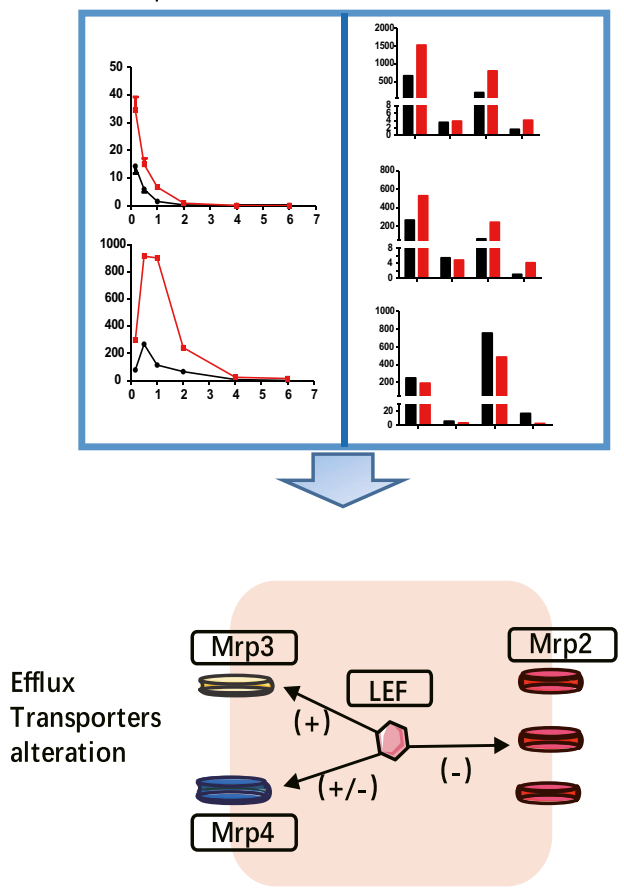

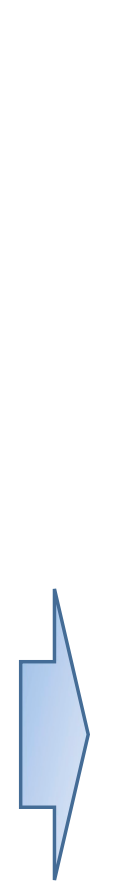

\section{Hepatocytes}

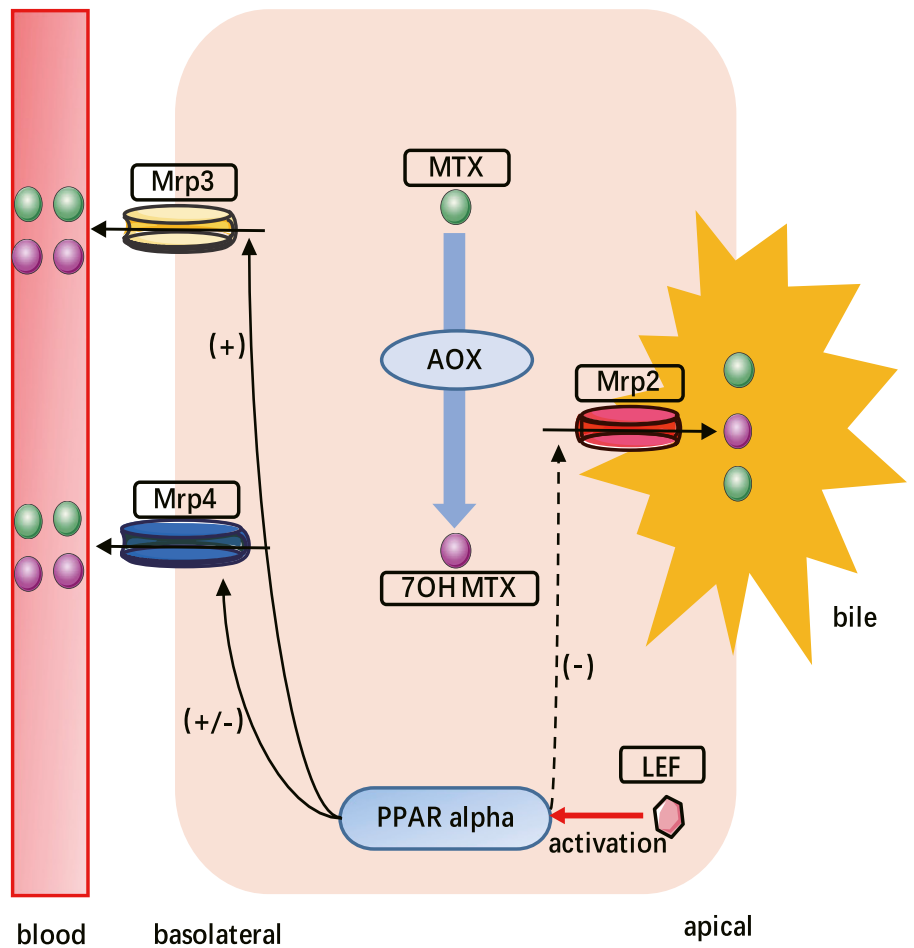

Fig. 8. Model of how LEF increases exposure to MTX and 7OH MTX via PPAR $\alpha$ activation and Mrp2/3 alterations in the mouse liver. MTX transforms to 7OH MTX through AOX activity. Both MTX and 7OH MTX are substrates of Mrp2/3. LEF downregulated Mrp2 and upregulated Mrp3 (both gene and protein levels) and Mrp4 (only gene level). Through Mrp2 downregulation, the biliary efflux of MTX/7OH MTX was damaged. Through Mpr3 (major) and Mrp4 (minor) upregulation, the concentrations of MTX and 7OH MTX in the plasma and kidneys were increased. Because the upregulation of Mrp3 did not completely compensate for the downregulation of Mrp2, LEF increased MTX/7OH MTX accumulation in the liver. 
Manautou, 2010). Thus, we speculated that LEF decreased MTX and 7OH MTX clearance, likely primarily by activating $\operatorname{PPAR} \alpha$ and subsequently altering Mrp2/3 function in the liver. No protein upregulation of Mrp4 after LEF treatment indicated that Mrp4 probably a negligible contribution for increased basolateral efflux of MTX/7OH MTX.

To further confirm the role that PPAR $\alpha$ plays in this process, we investigated whether PPAR $\alpha$ inhibition could reverse the effect of LEF on MTX PK. When the specific PPAR $\alpha$ antagonist GW6471 was coadministered with LEF, the increase in the AUC of MTX was almost completely reversed (Fig. 7). This indicated that $\operatorname{PPAR} \alpha$ activation plays a key role in MTX PK alteration after LEF treatment. We also found that HET0016, an inhibitor of CYP4a, was not able to reverse the effect of LEF on the disposition of MTX in vivo (Fig. 7). This implies that there is no direct correlation between Cyp4a and Mrps. However, all of these findings suggest possible effects of other PPAR $\alpha$ agonists on the distributions of drugs that are substrates of Mrps (e.g., MTX). Interestingly, although LEF clearly altered the function of Mrps and altered MTX/7OH MTX PK, it did not directly cause significant liver toxicity. LEF did not elevate plasma aspartate transaminase and alanine transaminase levels, nor did it cause oxidative stress or cholestasis in mice (Supplemental Fig. 3). This result is consistent with the nonpathologic features of Mrp2/3 double-knockout mice reported in a previous study, which showed that Mrp2 and Mrp3 deficiency did not directly induce liver toxicity (Vlaming et al., 2009b), possibly because of the redundancy of several efflux transporters. In addition, because PPAR $\alpha$ activation also upregulated multidrug resistance transporter 3 and increased biliary phosphatidylcholine secretion, it may partly act as a compensatory mechanism for decreased Mrp2 function (Ghonem et al., 2014). Even though there is no toxicity directly induced by MTX/LEF, a nontoxic dose of LEF can cause decreased MTX/7OH MTX clearance and increased liver exposure by affecting the metabolic enzymes (minorly) and transporters (majorly) involved in the disposal of MTX/7OH MTX. This is likely to increase the risk of liver toxicity due to MTX after longterm administration of a combination of MTX and LEF in the clinic (Fig. 8).

PPAR $\alpha$ is a nuclear receptor that plays an important role in lipid metabolism regulation (Rakhshandehroo et al., 2010). LEF upregulated Cyp4a10/14, peroxisomal acyl-coenzyme A oxidase 1 , and carnitine palmitoyltransferase I, which play important roles in lipid metabolism and probably affect systemic energy metabolism through a mechanism similar to that of classic PPAR $\alpha$ agonists. However, because LEF has significant immunodepressive and Ahr induction effects, both of which also play essential roles in energy metabolism, the overall effect of LEF may be more complicated and requires further investigation (Tanos et al., 2012; Wang and Ye, 2015). Furthermore, previous reports indicated that Cyp4a family members are key regulators of blood pressure due to the metabolism of prohypertensive 20-hydroxyeicosatetraenoic acid (Capdevila et al., 2015). The significant upregulation of CYp4a10/14 by LEF may be associated with hypotension, which is a side effect of LEF treatment in the clinic according to U.S. Food and Drug Administration reports (http://www.ehealthme.com/ ds/leflunomide/hypotension/).

\section{Acknowledgments}

The authors thank Eric Xu (VARI-SIMM Center, Center for Structure and Function of Drug Targets, CAS Key Laboratory of Receptor Research, Shanghai Institute of Materia Medica, Chinese Academy of Sciences) for assistance with the luciferase assay experiment. We also thank the staff of the Institutional Technology Service Center of Shanghai Institute of Materia Medica for technical support.

\section{Authorship Contributions}

Participated in research design: Wang, Ma, Pan.

Conducted experiments: Wang, Liu, Xiao, Zhang, Xu.

Contributed new reagents or analytic tools: Lin.

Performed data analysis: Wang, Liu.

Wrote or contributed to the writing of the manuscript: Wang, Ma, Liu, Zhang, Zhou, Pan.

\section{References}

Aleksunes LM, Slitt AL, Maher JM, Augustine LM, Goedken MJ, Chan JY, Cherrington NJ, Klaassen CD, and Manautou JE (2008) Induction of Mrp3 and Mrp4 transporters during acetaminophen hepatotoxicity is dependent on Nrf2. Toxicol Appl Pharmacol 226:74-83.

Ashton RE, Millward-Sadler GH, and White JE (1982) Complications in methotrexate treatment of psoriasis with particular reference to liver fibrosis. J Invest Dermatol 79:229-232.

Bilasy SE, Essawy SS, Mandour MF, Ali EA, and Zaitone SA (2015) Myelosuppressive and hepatotoxic potential of leflunomide and methotrexate combination in a rat model of rheumatoid arthritis. Pharmacol Rep 67:102-114.

Capdevila JH, Wang W, and Falck JR (2015) Arachidonic acid monooxygenase: genetic and biochemical approaches to physiological/pathophysiological relevance. Prostaglandins Other Lipid Mediat 120:40-49.

Chan GNY, Hoque MT, and Bendayan R (2013) Role of nuclear receptors in the regulation of drug transporters in the brain. Trends Pharmacol Sci 34:361-372.

Curtis JR, Beukelman T, Onofrei A, Cassell S, Greenberg JD, Kavanaugh A, Reed G, Strand V, and Kremer JM (2010) Elevated liver enzyme tests among patients with rheumatoid arthritis or psoriatic arthritis treated with methotrexate and/or leflunomide. Ann Rheum Dis 69:43-47.

Dendooven A, De Rycke L, Verhelst X, Mielants H, Veys EM, and De Keyser F (2006) Leflunomide and methotrexate combination therapy in daily clinical practice. Ann Rheum Dis 65:833-834.

Fuskevåg OM, Kristiansen C, Lindal S, and Aarbakke J (2000) Maximum tolerated doses of methotrexate and 7-hydroxy-methotrexate in a model of acute toxicity in rats. Cancer Chemother Pharmacol 46:69-73.

Gabrielsson J and Weiner D (2012) Non-compartmental analysis, in Computational Toxicology (Reisfeld B and Mayeno AN, eds) vol. I, pp 377-389, Humana Press, Totowa, NJ.

Ghonem NS, Ananthanarayanan M, Soroka CJ, and Boyer JL (2014) Peroxisome proliferator-activated receptor $\alpha$ activates human multidrug resistance transporter 3/ATP-binding cassette protein subfamily B4 transcription and increases rat biliary phosphatidylcholine secretion. Hepatology 59:1030-1042.

Gonzalez FJ and Shah YM (2008) PPARalpha: mechanism of species differences and hepatocarcinogenesis of peroxisome proliferators. Toxicology 246:2-8.

$\mathrm{Gu}$ X and Manautou JE (2010) Regulation of hepatic ABCC transporters by xenobiotics and in disease states. Drug Metab Rev 42:482-538.

Iqbal J, Sun L, Cao J, Yuen T, Lu P, Bab I, Leu NA, Srinivasan S, Wagage S, Hunter CA, et al. (2013) Smoke carcinogens cause bone loss through the aryl hydrocarbon receptor and induction of Cyp1 enzymes. Proc Natl Acad Sci USA 110: 11115-11120.

Johnson DR and Klaassen CD (2002) Regulation of rat multidrug resistance protein 2 by classes of prototypical microsomal enzyme inducers that activate distinct transcription pathways. Toxicol Sci 67:182-189.

Kim HG, Han EH, Im JH, Lee EJ, Jin SW, and Jeong HG (2015) Caffeic acid phenethyl ester inhibits 3-MC-induced CYP1A1 expression through induction of hypoxia-inducible factor-1 $\alpha$. Biochem Biophys Res Commun 465:562-568.

Kitamura S, Nakatani K, Sugihara K, and Ohta S (1999) Strain differences of the ability to hydroxylate methotrexate in rats. Comp Biochem Physiol C Pharmacol Toxicol Endocrinol 122:331-336.

Kremer JM, Genovese MC, Cannon GW, Caldwell JR, Cush JJ, Furst DE, Luggen ME, Keystone E, Weisman MH, Bensen WM, et al. (2002) Concomitant leflunomide therapy in patients with active rheumatoid arthritis despite stable doses of methotrexate. A randomized, double-blind, placebo-controlled trial. Ann Intern Med 137:726-733.

Lawrence RC, Felson DT, Helmick CG, Arnold LM, Choi H, Deyo RA, Gabriel S, Hirsch R, Hochberg MC, Hunder GG, et al.; National Arthritis Data Workgroup (2008) Estimates of the prevalence of arthritis and other rheumatic conditions in the United States. Part II. Arthritis Rheum 58:26-35.

Lee SW, Park HJ, Kim BK, Han KH, Lee SK, Kim SU, and Park YB (2012) Leflunomide increases the risk of silent liver fibrosis in patients with rheumatoid arthritis receiving methotrexate. Arthritis Res Ther 14:R232.

Londono J, Santos AM, Santos PI, Cubidez MF, Guzman C, and Valle-Oñate R (2012) Therapeutic efficacy and safety of methotrexate + leflunomide in Colombian patients with active rheumatoid arthritis refractory to conventional treatment. Rev Bras Reumatol 52:837-845.

$\mathrm{Lu}$ YF, Xu YY, Jin F, Wu Q, Shi JS, and Liu J (2014) Icariin is a PPAR $\alpha$ activator inducing lipid metabolic gene expression in mice. Molecules 19:18179-18191. 
Maher JM, Aleksunes LM, Dieter MZ, Tanaka Y, Peters JM, Manautou JE, and Klaassen CD (2008) Nrf2- and PPAR alpha-mediated regulation of hepatic Mrp transporters after exposure to perfluorooctanoic acid and perfluorodecanoic acid. Toxicol Sci 106:319-328.

Mathieu MC, Lapierre I, Brault K, and Raymond M (2001) Aromatic hydrocarbon receptor $(\mathrm{AhR})$. AhR nuclear translocator- and p53-mediated induction of the murine multidrug resistance mdr1 gene by 3-methylcholanthrene and benzo(a) pyrene in hepatoma cells. J Biol Chem 276:4819-4827.

McInnes IB and Schett G (2011) The pathogenesis of rheumatoid arthritis. N Engl J Med 365:2205-2219.

Moffit JS, Aleksunes LM, Maher JM, Scheffer GL, Klaassen CD, and Manautou JE (2006) Induction of hepatic transporters multidrug resistance-associated proteins (Mrp) 3 and 4 by clofibrate is regulated by peroxisome proliferator-activated receptor alpha. J Pharmacol Exp Ther 317:537-545.

Ni X, Gao Y, Wu Z, Ma L, Chen C, Wang L, Lin Y, Hui L, and Pan G (2016) Functional human induced hepatocytes (hiHeps) with bile acid synthesis and transport capacities: a novel in vitro cholestatic model. Sci Rep 6:38694.

Payet B, Fabre I, Fabre G, and Cano JP (1988) Interactions between 7-hydroxymethotrexate and folinic acid in RAJI cells, in vitro. Cancer Lett 39: $45-58$.

Rakhshandehroo M, Knoch B, Müller M, and Kersten S (2010) Peroxisome proliferator-activated receptor alpha target genes. PPAR Res 2010:612089.

Rivera SP, Choi HH, Chapman B, Whitekus MJ, Terao M, Garattini E, and Hankinson O (2005) Identification of aldehyde oxidase 1 and aldehyde oxidase homologue 1 as dioxin-inducible genes. Toxicology 207:401-409.

Singh JA, Saag KG, Bridges SL, Jr, Akl EA, Bannuru RR, Sullivan MC, Vaysbrot E, McNaughton C, Osani M, Shmerling RH, et al.; American College of Rheumatology (2016) 2015 American College of Rheumatology guideline for the treatment of rheumatoid arthritis. Arthritis Care Res (Hoboken) 68:1-25.

Sugihara K, Kitamura S, Yamada T, Ohta S, Yamashita K, Yasuda M, and FujiiKuriyama Y (2001) Aryl hydrocarbon receptor (AhR)-mediated induction of xanthine oxidase/xanthine dehydrogenase activity by $2,3,7,8$-tetrachlorodibenzo-p-dioxin. Biochem Biophys Res Commun 281:1093-1099.

Tan KP, Wang B, Yang M, Boutros PC, Macaulay J, Xu H, Chuang AI, Kosuge K, Yamamoto M, Takahashi S, et al. (2010) Aryl hydrocarbon receptor is a transcriptional activator of the human breast cancer resistance protein (BCRP/ABCG2). Mol Pharmacol 78:175-185.

Tanos R, Murray IA, Smith PB, Patterson A, and Perdew GH (2012) Role of the Ah receptor in homeostatic control of fatty acid synthesis in the liver. Toxicol Sci 129: 372-379.

Teng S and Piquette-Miller M (2007) Hepatoprotective role of PXR activation and MRP3 in cholic acid-induced cholestasis. Br J Pharmacol 151:367-376.

Visser K and van der Heijde DM (2009) Risk and management of liver toxicity during methotrexate treatment in rheumatoid and psoriatic arthritis: a systematic review of the literature. Clin Exp Rheumatol 27:1017-1025.
Vlaming ML, Pala Z, van Esch A, Wagenaar E, de Waart DR, van de Wetering K, van der Kruijssen CM, Oude Elferink RP, van Tellingen O, and Schinkel AH (2009a) Functionally overlapping roles of Abcg2 (Bcrp1) and Abcc2 (Mrp2) in the elimination of methotrexate and its main toxic metabolite 7-hydroxymethotrexate in vivo. Clin Cancer Res 15:3084-3093.

Vlaming ML, van Esch A, Pala Z, Wagenaar E, van de Wetering K, van Tellingen O, and Schinkel AH (2009b) Abcc2 (Mrp2), Abcc3 (Mrp3), and Abcg2 (Bcrp1) are the main determinants for rapid elimination of methotrexate and its toxic metabolite 7-hydroxymethotrexate in vivo. Mol Cancer Ther 8:3350-3359.

Vollrath V, Wielandt AM, Iruretagoyena M, and Chianale J (2006) Role of Nrf2 in the regulation of the Mrp2 (ABCC2) gene. Biochem $J$ 395:599-609.

Wang $\mathrm{H}$ and Ye J (2015) Regulation of energy balance by inflammation: common theme in physiology and pathology. Rev Endocr Metab Disord 16:47-54.

Weinblatt ME, Dixon JA, and Falchuk KR (2000) Serious liver disease in a patient receiving methotrexate and leflunomide. Arthritis Rheum 43:2609-2611.

Weinblatt ME, Kremer JM, Coblyn JS, Maier AL, Helfgott SM, Morrell M, Byrne VM, Kaymakcian MV, and Strand V (1999) Pharmacokinetics, safety, and efficacy of combination treatment with methotrexate and leflunomide in patients with active rheumatoid arthritis. Arthritis Rheum 42:1322-1328.

Widemann BC and Adamson PC (2006) Understanding and managing methotrexate nephrotoxicity. Oncologist 11:694-703.

Wiśniewski JR, Zougman A, Nagaraj N, and Mann M (2009) Universal sample preparation method for proteome analysis. Nat Methods 6:359-362.

Xiong H, Yoshinari K, Brouwer KLR, and Negishi M (2002) Role of constitutive androstane receptor in the in vivo induction of Mrp3 and CYP2B1/2 by phenobarbital. Drug Metab Dispos 30:918-923.

Xu HE, Stanley TB, Montana VG, Lambert MH, Shearer BG, Cobb JE, McKee DD, Galardi CM, Plunket KD, Nolte RT, et al. (2002) Structural basis for antagonistmediated recruitment of nuclear co-repressors by PPARalpha. Nature 415: 813-817.

Xu S, Weerachayaphorn J, Cai SY, Soroka CJ, and Boyer JL (2010) Aryl hydrocarbon receptor and NF-E2-related factor 2 are key regulators of human MRP4 expression. Am J Physiol Gastrointest Liver Physiol 299:G126-G135.

Yang Q, Nagano T, Shah Y, Cheung C, Ito S, and Gonzalez FJ (2008) The PPAR alpha-humanized mouse: a model to investigate species differences in liver toxicity mediated by PPAR alpha. Toxicol Sci 101:132-139.

Zachariae H, Heickendorff L, and Søgaard H (2001) The value of amino-terminal propeptide of type III procollagen in routine screening for methotrexate-induced liver fibrosis: a 10-year follow-up. Br J Dermatol 144:100-103.

Address correspondence to: Guoyu Pan, Shanghai Institute of Materia Medica, University of Chinese Academy of Sciences, 501 Haike Road, Shanghai 201203, China. E-mail: gypan@simm.ac.cn 